\title{
Growth in catheter biofilms and antibiotic resistance of Mycobacterium avium
}

\author{
Correspondence \\ Joseph O. Falkinham III \\ jofiii@vt.edu
}

Received 7 September 2006

Accepted 25 October 2006
Joseph O. Falkinham, III

\begin{abstract}
Department of Biological Sciences, Virginia Polytechnic Institute and State University, Blacksburg, VA 24061, USA
\end{abstract}

\section{INTRODUCTION}

Catheter-associated infections have been reported for Mycobacterium avium (Schelonka et al., 1994), Mycobacterium neoaurum (Davison et al., 1988; George \& Schlessinger, 1999; Holland et al., 1994; Woo et al., 2000), the M. neoaurum-like species Mycobacterium laticola (Kiska et al., 2004), Mycobacterium fortuitum (Flynn et al., 1988; Raad et al., 1991) and Mycobacterium chelonae (Flynn et al., 1988; Raad et al., 1991). These reports all establish that either slowly or rapidly growing mycobacteria isolated from catheters should not be dismissed as laboratory contaminants, but that catheter-associated infection should be considered.

As part of our continuing studies of the ecology of M. avium and how habitats occupied by this environmental opportunistic pathogen result in human infection, we have investigated the role of biofilms in M. avium persistence in drinking water systems (Steed \& Falkinham, 2006). Measurement of numbers of $M$. avium in drinking water systems throughout the world have shown that the majority of $M$. avium cells are in biofilms on pipe surfaces and low numbers are recovered from bulk water (Falkinham et al., 2001; Torvinen et al., 2004). Other mycobacteria, specifically Mycobacterium kansasii (Schulze-Röbbecke \& Fischeder, 1989), M. chelonae (Schulze-Röbbecke et al., 1992), M. fortuitum (Hall-Stoodley \& Lappin-Scott, 1998) and Mycobacterium phlei (Bardouniotis et al., 2001) also form biofilms on surfaces, including high density polyethylene and silastic rubber. It is likely that the high cell surface hydrophobicity of mycobacteria (Van Oss et al., 1975) contributes to biofilm formation. Such a predilection for attachment would also lead to colonization of catheter surfaces.

Counts of mycobacteria growing on surfaces have not been reported in published accounts of mycobacterial catheter-associated infections. Further, there have been no published data on attachment, growth and biofilm formation in catheter tubing by mycobacteria. Based on the observation that cells of other pathogenic micro-organisms grown in biofilms are more resistant to antimicrobial agents (Bardouniotis et al., 2001, 2003; Donlon, 2001; Nickel et al., 1985), it is likely that biofilm-grown cells of M. avium in catheters are relatively antibiotic-resistant compared to cells grown in suspension. Herein is reported the attachment, growth and antibiotic susceptibility of $M$. avium cells grown in suspension and in catheter biofilms.

\section{METHODS}

M. avium strain and growth. M. avium strain A5, which was originally recovered from an AIDS patient (Beggs et al., 1995), was cultured on Middlebrook 7H10 agar (BBL Microbiology Systems) supplemented with $0.5 \%(\mathrm{v} / \mathrm{v})$ glycerol and $10 \%(\mathrm{v} / \mathrm{v})$ oleic acid albumin (M7H10) and incubated for 7 days at $37^{\circ} \mathrm{C}$. A single transparent colony was picked and used to inoculate $2 \mathrm{ml}$ Middlebrook $7 \mathrm{H} 9$ broth, with the same supplements, in a $16 \times 125 \mathrm{~mm}$ screwcapped tube. The resulting inoculum culture was incubated at $37^{\circ} \mathrm{C}$ for 7 days without shaking and streaked on Plate Count Agar (Difco) for contaminants and M7H10 agar to confirm colony morphology. One millilitre of culture was used to inoculate $9 \mathrm{ml} \mathrm{M} 7 \mathrm{H} 9$ in a $20 \times 150 \mathrm{~mm}$ screw-capped tube and incubated at $37^{\circ} \mathrm{C}$ for 7 days with aeration by rotation to produce exponential phase growth. If the $10 \mathrm{ml}$ culture was found to be free from contaminants and had the correct transparent colonial morphology, it was refrigerated and could be used for up to 2 weeks.

Catheter biofilm apparatus. A CADD-Legacy 1 Ambulatory Infusion Pump model 6400 (SIMS Deltec) with $50 \mathrm{ml}$ reservoir was used for the experiments. The tubing was composed of polyvinyl chloride plasticized with trioctyl trimellitate, acrylonitrile-butadienestyrene, polycarbonate and silicone, and had an interior diameter of $0.1 \mathrm{~cm}$. The calculated volume and surface area for the tubing was 
$0.01 \mathrm{ml}$ and $0.314 \mathrm{~cm}^{2} \mathrm{~cm}^{-1}$ length. The pump and tubing system was chosen because of its widespread use in the United States. The tubing material is used in catheters from a variety of suppliers.

Catheter apparatus inoculation. Following assembly of the infusion pump and attachment of the catheter tubing, the reservoir was filled with $49.5 \mathrm{ml}$ autoclaved Blacksburg tap water (assimilable organic carbon $=500 \mu \mathrm{g} \mathrm{l}^{-1}$ ) and inoculated with $0.5 \mathrm{ml} \mathrm{M} 7 \mathrm{H} 9$ broth-grown culture (approx. $2 \times 10^{6}$ c.f.u. $\mathrm{ml}^{-1}$ ). The number of c.f.u. ( $\mathrm{ml}$ reservoir suspension $)^{-1}$ was measured by serial dilution in autoclaved Blacksburg tap water and spreading $0.1 \mathrm{ml}$ on M7H10 agar in triplicate for each dilution. The filled reservoir was attached and the pump adjusted to a flow rate of $7 \mathrm{ml} \mathrm{day}^{-1}$ (flow speed $\left.=0.5 \mathrm{~cm} \mathrm{~min}^{-1}\right)$. For the experiments reported here the pump was operated at $25^{\circ} \mathrm{C}$ (to mimic normal patient usage) from 7 am to $5 \mathrm{pm}$ daily $(10 \mathrm{~h}$ ), with $3 \mathrm{ml}$ medium consumed per day.

Adherence measurements. Immediately and at 2, 4, 6 and $24 \mathrm{~h}$ after initiation of flow, the pump was turned off and a $10 \mathrm{~cm}$ $\left(0.1 \mathrm{ml}\right.$ culture and $3.14 \mathrm{~cm}^{2}$ surface area) section through which the culture had flowed for the designated time was aseptically removed using an ethanol-sterilized razor blade. Usually this was the end of the tubing and the total length of tubing was calculated based on the number of samples required. The pump was restarted with no more than a 2 min delay in anticipation of collection of sequential samples. To estimate reproducibility, multiple sections were cut and processed as described below. The interior of each section was rinsed with $2 \mathrm{ml}$ autoclaved Blacksburg tap water delivered with a 20 -gauge needle and syringe at a rate of $0.5 \mathrm{ml} \mathrm{s}^{-1}$. The exterior surface of the tubing was sterilized by rolling it across an ethanolwet tissue, and the tubing cut longitudinally into two separate pieces aseptically using an ethanol-sterilized razor blade. The halves were cut longitudinally again and then cut across at approximately $1 \mathrm{~cm}$ intervals. Using flame-sterilized forceps, the resulting pieces were transferred to a $16 \times 125 \mathrm{~mm}$ screw-capped tube containing $5 \mathrm{ml}$ autoclaved Blacksburg tap water, where they were completely immersed, and vortexed for $120 \mathrm{~s}$ at the highest setting to suspend the biofilm. Samples $(0.1 \mathrm{ml})$ of the resulting suspension were spread on five $\mathrm{M} 7 \mathrm{H} 10$ agar plates and incubated at $37^{\circ} \mathrm{C}$ for 14 days and colonies counted. The results are reported as the number of $M$. avium c.f.u. $\mathrm{cm}^{-2}$ of catheter tubing surface.

Growth measurements. Following $24 \mathrm{~h}$ adherence, the reservoir containing the cells of $M$. avium strain A5 was replaced with a new sterile reservoir to which was added $50 \mathrm{ml}$ autoclaved Blacksburg tap water. The catheter tubing was rinsed with $50 \mathrm{ml}$ autoclaved Blacksburg tap water using a syringe with a 20 -gauge needle at a rate of $0.5 \mathrm{ml} \mathrm{s}^{-1}$. At 1, 2, 4, 7, 10 and 14 days, at least two $10 \mathrm{~cm}$ tubing sections were removed as described above and the number of M. avium in the biofilm measured as described for adherence. The results are reported as the number of $M$. avium c.f.u. $\mathrm{cm}^{-2}$ of catheter tubing surface.

Antibiotic susceptibility measurements of cells in suspension. A $0.1 \mathrm{ml}$ sample of the suspension flowing from the end of the catheter tubing after 7 days incubation was collected and $0.05 \mathrm{ml}$ diluted with $4.95 \mathrm{ml}$ autoclaved Blacksburg tap water (approx. $2.5 \times 10^{4}$ c.f.u. $\mathrm{ml}^{-1}$ ). The suspension was divided into $1 \mathrm{ml}$ aliquots, each in a $13 \times 100 \mathrm{~mm}$ sterile capped tube, and either clarithromycin or rifamycin was added to a final concentration of $100 \mu \mathrm{g} \mathrm{ml}^{-1}$ for each of two tubes. The fifth tube was a no-antibiotic control. For M. avium strain A5, the MIC for clarithromycin was $1 \mu \mathrm{g} \mathrm{ml}^{-1}$ and for rifamycin $0.5 \mu \mathrm{g} \mathrm{ml}^{-1}$. The concentration of $100 \mu \mathrm{g}$ antibiotic $\mathrm{ml}^{-1}$ chosen for the experiments was based on the observation that the chlorine-resistance of biofilm-grown cells of $M$. avium was 100-fold higher than that of suspension-grown cells (Steed \& Falkinham, 2006). Immediately and after 1, 2 and $3 \mathrm{~h}$ of incubation at room temperature, the surviving c.f.u. $\mathrm{ml}^{-1}$ in each of the five tubes was measured by spreading $0.1 \mathrm{ml}$ on M7H10 agar medium in triplicate and incubating at $37^{\circ} \mathrm{C}$ for $7-14$ days. The results are reported as percentage survival of cells compared to the no-antibiotic control.

Antibiotic susceptibility measurements of cells in catheter biofilms. After 7 days incubation (exponential phase, biofilm growth), the pump was turned off and twenty-four $10 \mathrm{~cm}$ sections through which the culture had flowed were aseptically removed using an ethanol-sterilized razor blade. The sections were treated as described for adherence measurements. For each of the two antibiotics and the antibiotic-free control, tubing pieces from a $10 \mathrm{~cm} \mathrm{sec-}$ tion were transferred to four $16 \times 125 \mathrm{~mm}$ screw-capped tubes containing $5 \mathrm{ml}$ autoclaved Blacksburg tap water. Clarithromycin or rifamycin was added to two sets of four tubing pieces to final concentrations of $100 \mu \mathrm{g} \mathrm{ml}^{-1}$ and the third set served as the antibiotic-free control. Immediately, and after 1,2 and $3 \mathrm{~h}$ incubation at room temperature, one tube from each set was vortexed, as above, to suspend the biofilm. Based on acid-fast fluorescent microscopy (Strahl et al., 2001) more than $95 \%$ of the adherent cells were removed. The remaining c.f.u. $\mathrm{ml}^{-1}$ were measured by spreading $0.1 \mathrm{ml}$ each suspension on M7H10 agar medium in triplicate and incubating plates at $37^{\circ} \mathrm{C}$ for $7-14$ days. The results are reported as the percentage of remaining c.f.u. for each time point for each treatment compared to the no-antibiotic control.

Statistical analysis. Values for survival following antibiotic exposure were compared by Student's $t$-test or ANOVA using InStat, version 3.0 (GraphPad Software).

\section{RESULTS AND DISCUSSION}

\section{Experimental approach}

The same experimental approach was employed for adherence, growth and antibiotic susceptibility measurements. First, the catheter tubing was primed with autoclaved Blacksburg tap water, and second, the reservoir for the catheter pump was filled with the same, and inoculated with $M$. avium strain A5 to yield a density of approximately $2 \times 10^{6}$ c.f.u. $\mathrm{ml}^{-1}$ (approx. 100-fold dilution of the M7H9 broth culture). After the reservoir had been attached to the pump and catheter tubing, the pump was started and samples collected at different times. For growth experiments, the reservoir containing the M. avium suspension was replaced with sterile tap water after $24 \mathrm{~h}$, and the tubing rinsed before the pump was restarted. Samples were collected from the distal portion of the tubing through which the water or suspension had flowed for the specific time period. In our experience, colonization of mycobacteria on the surface of catheter tubing was not uniform requiring that long sections of catheter tubing $(10 \mathrm{~cm})$ were sampled at least twice. That practice resulted in good reproducibility of the measurements from independent experiments.

\section{Adherence of $M$. avium to catheter tubing}

In Table 1 the mean c.f.u. $\mathrm{cm}^{-2}( \pm \mathrm{SD})$ of M. avium cells adhering to the catheter tubing at different times for four independent experiments is shown. The only colony types recovered from the adherence measurements were transparent, as was the isolate used for inoculating the 
Table 1. Adherence of $M$. avium strain A5 cells to catheter tubing

The numbers of $M$. avium cells adhering to catheter tubing upon exposure of tubing to $2 \times 10^{6}$ c.f.u. $M$. avium $\mathrm{ml}^{-1}$ are given. Numbers are expressed as the means $( \pm S D)$ of four independent experiments.

\begin{tabular}{|lc|}
\hline $\begin{array}{l}\text { Duration of } \\
\text { adherence (h) }\end{array}$ & $\begin{array}{c}\text { No. of adhering cells } \\
\text { (c.f.u. } \text { cm }^{-2} \text { catheter tubing } \pm \text { SD) }\end{array}$ \\
\hline 0 & $<3.2$ \\
2 & $9.0 \pm 4.4$ \\
4 & $25.6 \pm 3.7$ \\
6 & $30.1 \pm 2.1$ \\
24 & $356 \pm 63.3$ \\
\hline
\end{tabular}

cultures and suspensions. The measurements were limited to $24 \mathrm{~h}$ to reduce the impact of any increase in cell number in the reservoir suspension or tubing (suspension and adherent cells) due to growth. After 4 and $6 \mathrm{~h}$ of adherence, numbers of $M$. avium equalled those in drinking water biofilms (Falkinham et al., 2001; Torvinen et al., 2004) and artificial systems with other mycobacteria and surfaces (Bardouniotis et al., 2001, 2003; Hall-Stoodley \& LappinScott, 1998; Hall-Stoodley et al., 1999; Schulze-Röbbecke \& Fischeder, 1989) including M. avium (Carter et al., 2003). The observation that there was no increase in adherent cells from 4 to $6 \mathrm{~h}$ (Table 1) was repeatable and may be due to the possibility that not all cells in the suspension were capable of adherence due to growth stage differences. The number of M. avium cells at $24 \mathrm{~h}$ could be due to both adherence and growth of adherent cells. Unfortunately, no surface counts were provided in previous reports of catheter-related mycobacterial infections for comparison. The influence of different flow rates or cation and anion concentrations was not investigated.

\section{Growth of M. avium in catheter biofilms}

To measure growth certain precautions were required. The pump was turned off at $24 \mathrm{~h}$ and the reservoir switched to one containing only sterile Blacksburg tap water. Furthermore, the entire length of the catheter tubing was rinsed with autoclaved Blacksburg tap water. Thus, increase in numbers due to further adherence and growth of the mycobacterial cells in the reservoir and tubing did not contribute to numbers of adherent cells, and only increase in the number of already adherent cells was measured. Cells of M. avium strain A5 grew on the surfaces of the catheter tubing (Fig. 1). The numbers were reproducible and reached very high densities by 4 weeks (almost $7 \times 10^{4}$ c.f.u. $\mathrm{cm}^{-2}$ ). The uneven distribution of cells and colonies in the catheter tubing undoubtedly contributed to the variation in the c.f.u. values. It is likely that the drop from $24 \mathrm{~h}$ (end of adsorption period, Table 1$)$ to $48 \mathrm{~h}(0$ time, Fig. 1) reflected the absence of any contribution of the inoculated reservoir $\left(2 \times 10^{6}\right.$ c.f.u. $\mathrm{ml}^{-1}$ at $\left.24 \mathrm{~h}\right)$ and rinsing the complete length of the catheter tubing with

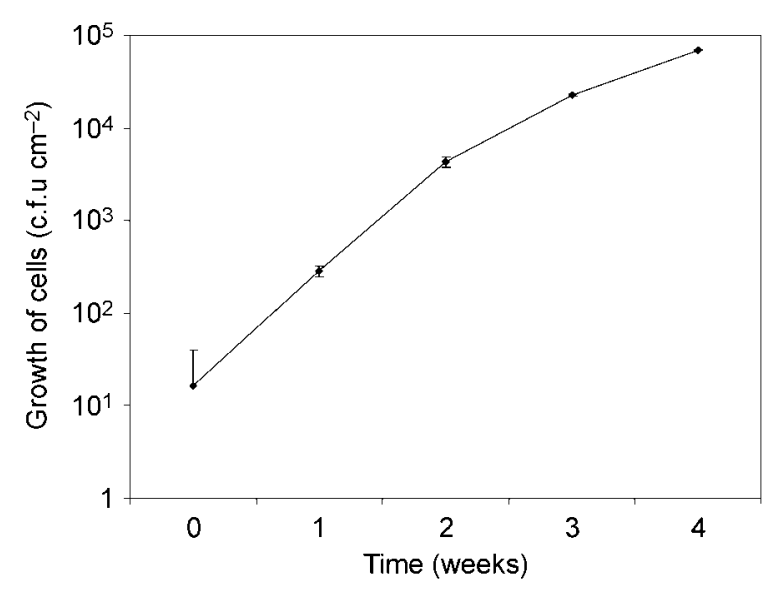

Fig. 1. Growth of $M$. avium strain $A 5$ in catheter biofilms. The number of $M$. avium cells is expressed as c.f.u. $\mathrm{cm}^{-2}$ following a $24 \mathrm{~h}$ adherence period and $24 \mathrm{~h}$ circulation of sterile tap water (time $0=48 \mathrm{~h}$ ). Incubation was at $25^{\circ} \mathrm{C}$. Values are expressed as the means $( \pm S D)$ of two independent experiments.

autoclaved Blacksburg tap water. Only transparent colony types were recovered from the growth measurements, so there was no change or selection for other types (e.g. opaque or rough). The plot of c.f.u. $\mathrm{cm}^{-2}$ against duration of incubation (Fig. 1) demonstrated that the increase in $M$. avium strain A5 numbers was exponential over the first 2 weeks of incubation (doubling time 2.45 days) and stationary phase had not been reached by 4 weeks (Fig. 1). This doubling time is remarkable considering that cells were in a medium consisting essentially of autoclaved tap water at $25^{\circ} \mathrm{C}$. The doubling times for cells growing in biofilms have been reported for $M$. phlei (0.4 days; Bardouniotis et al., 2001), Mycobacterium marinum (0.45 days; Bardouniotis et al., 2003) and $M$. fortuitum (0.3 and 0.18 days; Bardouniotis et al., 2003 and Hall-Stoodley \& Lappin-Scott, 1998, respectively). Although these reported doubling times are considerably shorter, they were measured under conditions where growth of adherent cells and continued adherence of cells from suspension both contributed to the increased accumulation of cells on the surfaces. Further, in all those studies, cells were grown in Middlebrook $7 \mathrm{H} 9$ broth at $37^{\circ} \mathrm{C}$, which would substantially increase growth rates.

\section{Antibiotic susceptibility of $M$. avium in catheter biofilms}

Antibiotic susceptibility was measured against three types of M. avium strain A5 cells: (1) cells were grown for 1 week in catheter biofilms and exposed to the antibiotics while in the biofilm (sessile), (2) cells grown for 1 week in biofilms were harvested from catheter tubing (liberated cells) and exposed to the antibiotics in suspension, (3) cells grown in suspension for 1 week were collected from the water flowing through catheter tubing (planktonic cells) and exposed to 
antibiotics. All cell types were exposed to $100 \mu \mathrm{g}$ clarithromycin $\mathrm{ml}^{-1}$ or $100 \mu \mathrm{g}$ rifamycin $\mathrm{ml}^{-1}$ for $0,1,2$ and $3 \mathrm{~h}$. The results, listed in Table 2 (mean \pm SD for two independent experiments), document the variation in numbers of surviving cells exposed to antibiotics in biofilms (sessile) or harvested and suspended (liberated) compared to those of cells grown in suspension (planktonic). The variation in counts (Table 2) is likely due to the presence of aggregates in planktonic and liberated cells that might be incompletely dispersed. For cells exposed to antibiotics in biofilms, the major reason for the variation in numbers is the uneven distribution of cells and microcolonies along the length of the catheter tubing. In spite of this variation, the trends are clear and demonstrate that survival of cells of $M$. avium strain A5 cells grown in biofilms was significantly higher than that of cells in suspension (Student's $t$-test, $P<0.05$ ). There was no significant difference between the susceptibility of cells grown in biofilms and exposed in either the biofilm or in suspension (Table 2). Possibly the relatively low density and immaturity (e.g. absence of an extracellular matrix) of the biofilm was responsible. It is unlikely that aggregation contributed to antibiotic resistance due to reduced penetration of the antibiotics. Microscopic examination of the suspensions showed that the largest aggregates were 25 colonies or fewer and the biofilms consisted of monolayers of cells and small microcolonies (fewer than 100 cells colony ${ }^{-1}$ ). Such aggregates would not prevent antibiotic penetration in the time-frames employed here (Nichols et al., 1989). Only transparent colonies were detected amongst the survivors, indicating that antibiotic exposure did not select for an alternative type. This is expected, because the transparent types are more antibiotic resistant than opaque colony types (Woodley \& David, 1976). Quite possibly, antibiotic exposure of biofilms of opaque $M$. avium variants might lead to selection for transparent variants. The fact that the cells grown in catheter biofilms and exposed to antibiotics in suspension were as resistant to the antibiotics as were cells exposed in biofilms, suggests that physiological changes, leading to antibiotic resistance, occur in M. avium cells when grown on surfaces. The same was noted for cells of $M$. avium grown on glass biofilms and exposed to chlorine (Steed \& Falkinham, 2006).

The data demonstrate that cells of M. avium adhere to and grow on a type of catheter surface and are consistent with reports of catheter-related mycobacterial infections, including those due to M. avium (Schelonka et al., 1994). Although the growth rate of $M$. avium strain A5 was rather slow ( 2.45 days doubling ${ }^{-1}$ ), it was sufficient to generate a substantial biofilm population in tap water after 2 weeks (Table 2). Based on earlier data showing that the majority of M. avium cells in drinking water systems are in biofilms on pipe surfaces (Falkinham et al., 2001; Torvinen et al., 2004), our strategy for isolating, detecting and enumerating mycobacteria now focuses on surfaces as the samples of choice.

The fact that cells of $M$. avium grown on catheter surfaces are significantly more resistant to antibiotics than cells grown in suspension is in agreement with similar studies with other pathogens, including Pseudomonas aeruginosa (Nickel et al., 1985). Furthermore, the antibiotic-resistance of catheter-biofilm-grown $M$. avium has implications for treatment of infected patients and methods for measuring antibiotic susceptibility of $M$. avium and probably other mycobacteria. Cells of M. avium strain A5 grown in biofilms, liberated and exposed to antibiotics in suspension were more resistant than cells grown in suspension (Table 2). In

Table 2. Antibiotic susceptibility of $M$. avium strain A5 cells grown in suspension and in biofilms

Antibiotic susceptibility is expressed as the survival of M. avium strain A5 cells following exposure to antibiotics in suspension or in biofilms. Values are the means $( \pm S D)$ for two independent experiments.

\begin{tabular}{|lccc|}
\hline Cell growth and exposure & Duration of exposure $(\mathbf{h})$ & \multicolumn{2}{c|}{ Percentage survival \pm SD } \\
\cline { 2 - 3 } & & Clarithromycin & Rifamycin \\
\hline Grown and exposed in suspension & 0 & 100 & 100 \\
& 1 & $19 \pm 3$ & $62 \pm 6$ \\
Grown in biofilms exposed in suspension & 2 & $8 \pm 0.6$ & $17 \pm 0.3$ \\
& 3 & $2 \pm 0.7$ & $7 \pm 0.8$ \\
Grown and exposed in biofilms & 0 & 100 & 100 \\
& 1 & $42 \pm 24$ & $135 \pm 10$ \\
& 2 & $31 \pm 12$ & $100 \pm 27$ \\
& 3 & $44 \pm 12$ & $94 \pm 21$ \\
& 0 & 100 & 100 \\
& 1 & $156 \pm 65$ & $107 \pm 15$ \\
& 2 & $79 \pm 43$ & $68 \pm 22$ \\
& 3 & $73 \pm 51$ & $158 \pm 16$ \\
\hline
\end{tabular}


contrast, cells of $P$. aeruginosa grown in biofilms liberated and exposed to antibiotics in suspension were as susceptible to antibiotics as were planktonic cells (Anwar et al., 1989). Thus, it would appear that biofilm growth leads to a physiological change, reflected here as antibiotic resistance. Because cells liberated from catheter biofilms were as resistant to antibiotics as were cells exposed in biofilms, antibiotic concentrations based on results of the susceptibility of suspension-grown cells may be too low to kill or inhibit the growth of mycobacteria released from the catheter biofilms. Consequently, it may be necessary to develop methods for assessing MICs of mycobacteria grown in biofilms.

\section{ACKNOWLEDGEMENTS}

The loan of the catheter pump, the CAAD-Legacy 1 ambulatory infusion pump model 6400 (SIMS Deltec) through the generosity of Smiths Medical, MD, and their representative Ms Karyn Juricich, is acknowledged; the work could not have been accomplished without this. The author acknowledges the excellent technical assistance of Ms Myra D. Williams and the supporting funds provided by Applied Microbiology and Genetics. The author would like to thank Mr Steven R. Fleming of Brill, England for his hospitality during the preparation of the manuscript.

\section{REFERENCES}

Anwar, H., van Biesen, T., Dasgupta, M., Lam, K. \& Costerton, J. W. (1989). Interaction of biofilm bacteria with antibiotics in a novel in vitro chemostat system. Antimicrob Agents Chemother 33, 1824-1826.

Bardouniotis, E., Huddleston, W., Ceri, H. \& Olson, M. E. (2001). Characterization of biofilm growth and biocide susceptibility testing of Mycobacterium phlei using the MBEC(MM) assay system. FEMS Microbiol Lett 203, 263-267.

Bardouniotis, E., Ceri, H. \& Olson, M. E. (2003). Biofilm formation and biocide susceptibility testing of Mycobacterium fortuitum and Mycobacterium marinum. Curr Microbiol 46, 28-32.

Beggs, M. L., Crawford, J. T. \& Eisenach, K. D. (1995). Isolation and sequencing of the replication region of Mycobacterium avium plasmid pLR7. J Bacteriol 177, 4836-4840.

Carter, G., Wu, M., Drummond, D. C. \& Bermudez, L. E. (2003). Characteristics of biofilm formation by clinical isolates of Mycobacterium avium. J Med Microbiol 52, 747-752.

Davison, M. B., McCormack, J. G., Blacklock, Z. M., Dawson, D. J., Tilse, M. H. \& Crimmins, F. B. (1988). Bacteraemia caused by Mycobacterium neoaurum. J Clin Microbiol 26, 762-764.

Donlon, R. M. (2001). Biofilms and device-associated infections. Emerg Infect Dis 7, 277-281.

Falkinham, J. O. III, Norton, C. D. \& LeChevallier, M. W. (2001). Factors influencing numbers of Mycobacterium avium, Mycobacterium intracellulare, and other mycobacteria in drinking water distribution systems. Appl Environ Microbiol 67, 1225-1231.

Flynn, P. M., van Hooser, B. \& Gigliotti, F. (1988). Atypical mycobacteria infections of Hickman catheter exit sites. Pediatr Infect Dis 7, 510-513.
George, S. L. \& Schlessinger, L. S. (1999). Mycobacterium neoaurum - an unusual cause of infection of vascular catheters: case report and review. Clin Infect Dis 28, 682-683.

Hall-Stoodley, L. \& Lappin-Scott, H. (1998). Biofilm formation by the rapidly growing mycobacterial species Mycobacterium fortuitum. FEMS Microbiol Lett 168, 77-84.

Hall-Stoodley, L., Keevil, C. W. \& Lappin-Scott, H. M. (1999). Mycobacterium fortuitum and Mycobacterium chelonae biofilm formation under high and low nutrient conditions. $J$ Appl Microbiol Symp 85 (Suppl.), 60S-69S.

Holland, D. J., Chen, S. C. A., Chew, W. W. K. \& Gilbert, G. L. (1994). Mycobacterium neoaurum infection in a Hickman catheter in an immunosuppressed patient. Clin Infect Dis 18, 1002-1003.

Kiska, D. L., Turenne, C. Y., Dubansky, A. S. \& Domachowske, J. B. (2004). First case report of catheter-related bacteremia due to "Mycobacterium laticola". J Clin Microbiol 42, 2855-2857.

Nichols, W. W., Evans, M. J., Slack, M. P. E. \& Walmsley, H. L. (1989). The penetration of antibiotics into aggregates of mucoid and nonmucoid Pseudomonas aeruginosa. J Gen Microbiol 135, 1291-1303.

Nickel, J. C., Ruseska, I., Wright, J. B. \& Costerton, J. W. (1985). Tobramycin resistance of Pseudomonas aeruginosa cells growing as a biofilm on urinary catheter material. Antimicrob Agents Chemother 27, 619-624.

Raad, I. I., Vartivarian, S., Khan, A. \& Bodey, G. P. (1991). Catheterrelated infections caused by the Mycobacterium fortuitum complex: 15 cases and review. Rev Infect Dis 13, 1120-1125.

Schelonka, R. L., Asher, D. P., McMahon, D. P., Drehner, D. M. \& Kuskie, M. R. (1994). Catheter-related sepsis caused by Mycobacterium avium complex. Ped Infect Dis J 13, 236-238.

Schulze-Röbbecke, R. \& Fischeder, R. (1989). Mycobacteria in biofilms. Zentralbl Hyg Umweltmed 188, 385-390.

Schulze-Röbbecke, R., Janning, B. \& Fischeder, R. (1992). Occurrence of mycobacteria in biofilm samples. Tubercle Lung Dis 73, 141-144.

Steed, K. A. \& Falkinham, J. O., III (2006). Effect of growth in biofilms on chlorine susceptibility of Mycobacterium avium and Mycobacterium intracellulare. Appl Environ Microbiol 72, 4007-4011.

Strahl, E. D., Gillaspy, G. E. \& Falkinham, J. O., III (2001). Fluorescent acid-fast microscopy for measuring phagocytosis of Mycobacterium avium, Mycobacterium intracellulare, and Mycobacterium scrofulaceum by Tetrahymena pyriformis and their intracellular growth. Appl Environ Microbiol 67, 4432-4439.

Torvinen, E., Suomalainen, S., Lehtola, M. J., Miettinen, I. T., Zacheus, O., Paulin, L., Katila, M.-L. \& Martikainen, P. J. (2004). Mycobacteria in water and loose deposits of drinking water distribution systems in Finland. Appl Environ Microbiol 70, 1973-1981.

Van Oss, C. J., Gillman, C. F. \& Neumann, A. W. (1975). Phagocytic Engulfment and Cell Adhesiveness. New York: Marcel Dekker.

Woo, P. C. Y., Tsoi, H.-W., Leung, K.-W., Lum, P. N. L., Leung, A. S. P., Ma, C.-H., Kam, K.-M. \& Yuen, K.-Y. (2000). Identification of Mycobacterium neoaurum isolated from a neutropenic patient with catheter-related bacteremia by $16 \mathrm{~S}$ rRNA sequencing. $J$ Clin Microbiol 38, 3515-3517.

Woodley, C. L. \& David, H. L. (1976). Effect of temperature on the rate of the transparent to opaque colony type transition in Mycobacterium avium. Antimicrob Agents Chemother 9, 113-119. 